\title{
Myasthenia gravis: clinical and histological features in relation to thymectomy
}

\author{
M. A. SAMBROOK, H. REID, P. D. MOHR, AND H. G. BODDIE \\ From the University Department of Neurology, Manchester Royal Infirmary, Manchester
}

SYNOPSIS The clinical and thymic histological features of 23 patients who underwent thymectomy for myasthenia gravis have been examined and compared. Eighty-two per cent of patients with a nonneoplastic gland containing numerous germinal centres improved postoperatively, whereas $83 \%$ of patients with a non-neoplastic gland containing no germinal centres deteriorated or died. Glands with only slight involution and containing numerous germinal centres were more commonly seen in young female patients. The evidence relating thymic histological appearances with the postoperative progress of patients with myasthenia gravis is reviewed.

An association between myasthenia gravis and the thymus gland was first suggested by Weigert in 1901. Although Schumacher and Roth (1913) reported the clinical improvement of a patient with myasthenia after removal of an enlarged non-neoplastic gland, it was not until the reports of Blalock et al. (1939) and Keynes (1949) that the beneficial effect of thymectomy was fully appreciated. Keynes concluded that, although the connection between myasthenia and abnormalities of the thymus gland was well established, there was no clue to how or why the gland acquired its abnormal function.

Only recently have the histological appearances of the thymus gland and their relation to the clinical progress of patients after thymectomy received greater attention (Castleman and Norris, 1949; Mackay et al., 1968; Alpert et al., 1971 ; Seybold et al., 1971 ; Reinglass and Brickel, 1973; Vetters and Simpson, 1974). Opinions have varied from a clearly demonstrable association between thymic hyperplasia and postoperative improvement to a complete dissociation of these two parameters. It therefore seemed appropriate to make a clinical and pathological study of 23 myasthenic patients who had undergone thymectomy at the Manchester Royal Infirmary during the past 10 years.

(Accepted 14 August 1975.)

\section{METHODS}

PATIENTS Twenty-three patients with myasthenia gravis underwent thymectomy. Surgery was performed because of either increasing weakness despite treatment with anticholinesterases and in some cases steroids (19 patients) or the presence of a thymomac (four patients). At the time of operation all patients had evidence of ocular, bulbar, and limb weakness.

The average age at onset of symptoms of patients without a thymoma was 32.6 years (range, 16-68 years) and the mean duration of symptoms before thymectomy was 4.9 years. The sex distribution showed a predominance of females with a ratio of 2.2:1. Patients with a thymoma developed symptoms at $39,49,56$, and 65 years and the mean preoperative duration of symptoms was 1.0 year. Three of these patients were male.

HISTOLOGY Haematoxylin and eosin stained sections from all the paraffin blocks from each surgical section were examined by one of the authors (H.R.) without knowledge of the clinical details. The average number of sections to each specimen was three with a range of two to 10 . The criteria used for assessment included the degree of gland involution, the overall cellular composition and frequency of plasma cells, the frequency of germinal centres, the epithelial cell type, and the presence of perivascular lymphocytic cuffing or lake formation. The grading system used for these criteria was that of Alpert et al. (1971). The overall cellularity of the glands was estimated by comparison with sections from non-myasthenia thymectomy specimens from pat- 
TABLE 1

Clinical GROUPING, SEX, AGE AT ONSET, PREOPERATIVE DURATION OF SYMPTOMS, FOLLOW-UP, AND PRE- AND POSTOPERATIVE MEDICATION IN 19 PATIENTS WITH NON-THYMOMATOUS MYASTHENIA GRAVIS

\begin{tabular}{|c|c|c|c|c|c|c|c|c|c|c|c|c|}
\hline \multirow{3}{*}{$\begin{array}{c}\text { Clinical } \\
\text { group } \\
\text { (no.) }\end{array}$} & \multirow{3}{*}{$\begin{array}{c}\text { Mean } \\
\text { age at } \\
\text { onset } \\
\text { (yr; range) }\end{array}$} & \multirow{3}{*}{\multicolumn{2}{|c|}{$\begin{array}{c}\text { Preop. duration of symptoms } \\
(y r ; \text { range })\end{array}$}} & \multirow{2}{*}{\multicolumn{3}{|c|}{ Sex }} & \multicolumn{5}{|c|}{ Medication } & \multirow{3}{*}{$\begin{array}{c}\text { Follow- } \\
\text { up } \\
(y r)\end{array}$} \\
\hline & & & & & & & \multicolumn{2}{|c|}{ Steroids* } & \multicolumn{3}{|c|}{$\begin{array}{c}\text { Post-op. } \dagger \\
\text { anticholinesterase }\end{array}$} & \\
\hline & & & & $M$ & $F$ & $\stackrel{\%}{\%}$ female & Preop. & Postop. & + & $=$ & - & \\
\hline $\begin{array}{c}\text { A } \\
(8)\end{array}$ & $\begin{array}{c}23.1 \\
(16-36)\end{array}$ & $\begin{array}{l}3.5 \\
(1-8)\end{array}$ & 5.0 & 1 & 7 & $73 \%$ & $\begin{array}{c}5 \\
(\mathrm{SYN})\end{array}$ & $\begin{array}{c}1 \\
\text { (P) }\end{array}$ & 3 & 3 & 2 & $\begin{array}{c}3.1 \\
(0.8-8.0)\end{array}$ \\
\hline $\begin{array}{c}\text { B } \\
(3)\end{array}$ & $\begin{array}{c}31.3 \\
(26-35)\end{array}$ & $\begin{array}{c}9.2 \\
(0.5-15.0)\end{array}$ & $\int(0.5-15.0)$ & 2 & 1 & 100 & $\stackrel{2}{(\mathrm{SYN})}$ & $\begin{array}{c}1 \\
(\mathrm{SYN})\end{array}$ & 0 & 1 & 2 & $\begin{array}{c}1.4 \\
(0.8-3.0)\end{array}$ \\
\hline $\begin{array}{l}\text { C } \\
(8)\end{array}$ & $\begin{array}{c}42.6 \\
(16-68)\end{array}$ & $\begin{array}{c}4.7 \\
(0.3-26.0)\end{array}$ & & 3 & 5 & $63 \%$ & $\begin{array}{c}5 \\
(\mathrm{SYN}: \\
4 \mathrm{P}: 1)\end{array}$ & $\stackrel{4}{(S Y N)}$ & 2 & 4 & 2 & $\begin{array}{c}14 \\
(0.8-5.0)\end{array}$ \\
\hline
\end{tabular}

* SYN $=5$ day courses of tetracosactrin (Synacthen); $P=$ alternate day prednisolone.

$\dagger+$ : increased; = : same; - : reduced postoperatively.

ients of approximately the same age removed at the onset of operation for cardiac or chest surgery.

\section{RESULTS}

\section{Myasthenia and thymoma}

Four patients had a thymoma and all received preoperative radiotherapy. Postoperatively, two patients improved, one becoming virtually asymptomatic, while the remaining two showed no improvement.

All of the four surgically removed specimens contained a thymoma, three of which were of the epithelial type and one of the lymphoid type. One of the epithelial thymomas was considered to be of low grade malignancy. Residual thymic tissue was present in three specimens, none of which had germinal centres.

No correlation between the histological findings and the clinical progress of the patients could be made.

\section{Myasthenia not associated with thymoma}

PROGRESS AFTER THYMECTOMY For the purpose of clinical assessment patients were divided into three groups based upon their progress after thymectomy:

Group A-Complete remission or marked improvement.

Group B-Significant improvement.

Group C-No improvement, deterioration, or death.
Patients were reviewed at regular intervals and details of their most recent assessment, duration of follow-up, sex distribution, pre- and postoperative treatment, and allocation into these three groups are included below and in Table 1. The mean preoperative duration of symptoms and the sex ratio varied among the three groups but this probably reflected the small number in one of these groups. When those patients who had improved (groups A and B) were compared with those who had shown no improvement or had deteriorated (group C) the ratios for these factors were not significantly different (Table 1).

The mean age at onset of symptoms increased from group A (23.1 years) to group C (42.6 years). The postoperative interval before reaching group A ranged from six months to $2 \frac{1}{2}$ years. In six of the eight patients it was less than 12 months and in the other two it was 15 months and $2 \frac{1}{2}$ years.

Group $A$ (eight patients) One patient had a complete remission and was able to stop all anticholinesterase medication within four years of thymectomy. The remaining patients had improved markedly and were able to lead a fully active life with no restrictions. One patient had further improved with alternate-day prednisolone therapy and the improvement had been maintained on a maintenance dose of $10 \mathrm{mg}$ on alternate days.

Group $B$ (three patients) These patients had 
improved significantly but were still limited by their weakness. Two of them had been operated upon only nine months before assessment and were still improving, while the clinical state of the third patient who had undergone thymectomy $2 \frac{1}{2}$ years previously had remained the same for at least 12 months. One patient had benefited from a five-day course of tetracosactrin (Synacthen) $1 \mathrm{mg}$ daily.

Group $C$ (eight patients) Two patients in this group had shown no overall change when compared with their state immediately before thymectomy. Both had deteriorated shortly after thymectomy but improved again after a five-day course of tetracosactrin.

There were no immediate postoperative deaths. Six patients died within two months to five years after thymectomy. Three steadily deteriorated postoperatively and terminally had recurrent bronchopneumonia and respiratory failure. Two of these patients died in 1964 and 1966 and did not receive steroids, while a third continued to deteriorate despite their use. Three patients improved for periods ranging from two to 14 months after surgery. Two died suddenly at home, while the other patient had a more prolonged deterioration dominated by recurrent chest infection and the need for long periods of mechanical ventilation. Five-day courses of tetracosactrin were used postoperatively in this last patient and resulted in some temporary improvement but failed to have any permanent benefit.

One patient had a breast lump biopsied at the time of thymectomy which was subsequently found to be malignant and a simple mastectomy was performed several days later. There was no clinical or electromyographic evidence to indicate that this patient had the Eaton-Lambert syndrome.

HISTOLOGICAL FINDINGS Nineteen non-thymomatous glands were examined. The extent of involution was assessed as slight in eight specimens $(42 \%)$, moderate in seven $(37 \%)$, and severe in four $(21 \%)$. Germinal centres were numerous in 11 specimens $(58 \%)$, and the extent of involution was slight in eight of these and moderate in the remainder. Two $(11 \%)$ had occasional germinal centres in association with moderate involution and six $(31 \%)$ had no germinal centres with either moderate (two) or severe (four) involution.

The overall cellularity showed a lymphocytic predominance in $12(63 \%)$ specimens, an epithelial predominance in one $(5 \%)$ and a normocellular appearance in six $(32 \%)$. Plasma cells were rare in the majority $(68 \%)$ of specimens occurred occasionally in four $(21 \%)$, and were numerous in two $(11 \%)$. No correlation wasi found between lymphocytic predominance of an increased plasma cell frequency and those glands with numerous germinal centres. The epithelial cells were all of the plump type and only six specimens $(32 \%)$ showed perivascular lymphocytic cuffing; none showed lymphocytic lakes.

COMPARISON OF CLINICAL AND HISTOLOGICAL FINDINGS The predominant cell type, incidence of plasma cells, and frequency of perivascular lymphocytic cuffing were not significantly different between each of the three clinical groups. The extent of involution of the thymus gland was more variable, however. In group $\mathrm{A}$, five

TABLE 2

AGE AT ONSET OF SYMPTOMS AND SEX IN RELATION TO THE THYMIC HISTOLOGICAL FINDINGS IN 19 PATIENTS WITH NONTHYMOMATOUS MYASTHENIA GRAVIS

\begin{tabular}{|c|c|c|c|c|c|c|}
\hline & \multicolumn{3}{|c|}{ Germinal centres } & \multicolumn{3}{|c|}{ Involution } \\
\hline & Numerous & Occasional & Absent & Slight & Moderate & Severe \\
\hline $\begin{array}{l}\text { No. of patients } \\
\text { Mean age at onset (yr; range) } \\
\% \text { Females }\end{array}$ & $\begin{array}{c}11 \\
24.8 \\
(16-36) \\
82 \%\end{array}$ & $\begin{array}{c}2 \\
21 \& 40 \\
50 \%\end{array}$ & $\begin{array}{c}6 \\
47.7 \\
(19-69) \\
50 \%\end{array}$ & $\begin{array}{c}8 \\
24.5 \\
(16-36) \\
100 \%\end{array}$ & $\begin{array}{c}7 \\
25.9 \\
(16-40) \\
57 \%\end{array}$ & $\begin{array}{c}4 \\
61.0 \\
(47-69) \\
75 \%\end{array}$ \\
\hline
\end{tabular}




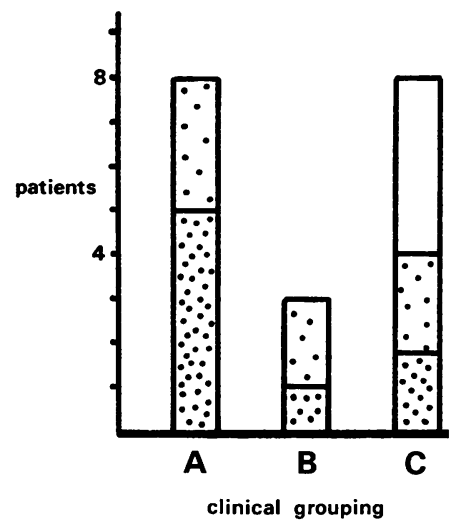

FIG. 1 The extent of gland involution in relation to the clinical grouping in 19 patients with non-thymomatous myasthenia gravis. Thymus gland involution: $\because::$ = slight, $\square . \cdot=$ moderate, $\square=$ severe .

of the eight glands and in group B, one of the three glands showed only slight atrophy and in the remainder it was described as moderate. None of the glands in groups A and B was severely atrophic and this contrasted with group $\mathrm{C}$ where $50 \%$ had undergone marked involution (Fig. 1).

The incidence of germinal centres was the most

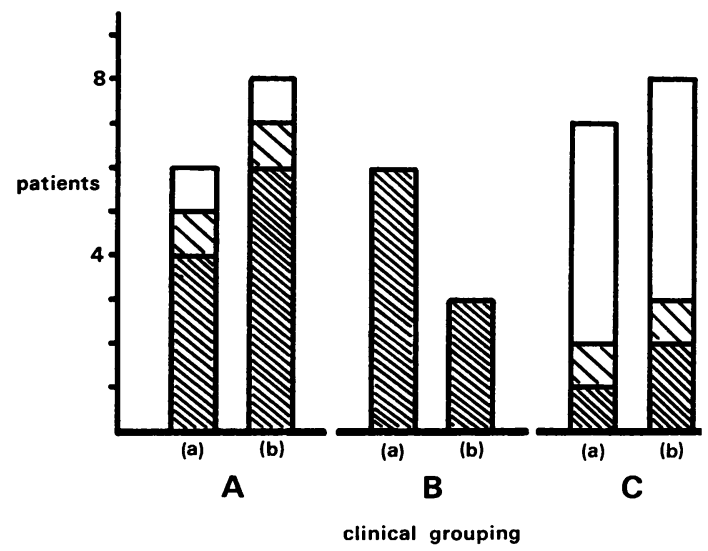

FIG. 2 The degree of germinal centre hyperplasia in relation to the clinical grouping (a) nine months postoperatively and (b) at most recent follow-up in 19 patients with non-thymomatous myasthenia gravis. Germinal centres: $\triangle M=$ numerous, $\triangle J \nabla=$ occasional, $\square=$ absent . notable histological feature. Ten of the eleven patients with glands showing numerous germinal centres had experienced either a moderate or marked improvement within nine months of thymectomy and at their most recent follow-up two patients in group B have further improved to join group A (Fig. 2). Two patients with this histological picture died at two months and five years after thymectomy. Five of the six patients with thymus glands containing no germinal centres failed to improve or died.

The age at onset of symptoms and the percentage of female patients varied among the different pathological groups (Table 2). The mean age of those patients with numerous germinal centres or slight gland involution was less than that for patients in whom germinal centres were absent or the gland was atrophic.

\section{DISCUSSION}

Sloan (1943) made a histological study of the thymus gland in 10 patients with myasthenia gravis and demonstrated that all the non-neoplastic glands contained an increased number of lymphocytes and that $70 \%$ had germinal centre hyperplasia. These appearances were not specific, however, and were also described in patients with hyperthyroidism, Addison's disease, acromegaly, and systemic lupus erythematosus (Sloan, 1943; McEachern and Parnall, 1948; Mackay and de Gail, 1963). Castleman and Norris (1949) confirmed these histological findings in myasthenia gravis and went on to relate the extent of germinal centre hyperplasia to the patient's postoperative progress but failed to demonstrate any correlation. Their results have been widely accepted, but it is notable that their index of clinical improvement was based primarily upon the postoperative decrease in neostigmine requirements and that the four patients who had improved most belonged to the group with the largest number of germinal centres.

Interest was reawakened by the suggestion of Goldstein (1966) that the thymic histological appearances were representative of an autoimmune reaction in the thymic medulla which caused the release of a neuromuscular blocking agent. Corroborative evidence came from the study of Mackay et al. (1968) which showed germinal centre hyperplasia to be most frequent 
in young females with non-involuted thymus glands who respond well to thymectomy. However, further reports have failed to confirm these results. Alpert et al. (1971) found that patients with germinal hyperplasia improved less frequently after thymectomy than those with occasional or absent germinal centres, although this could not be confirmed statistically. There was, however, a correlation between the degree of thymic hyperplasia and the length of the postoperative period before remission. On the basis of this observation they suggested that neuromuscular injury was mediated by thymic lymphocytes and the time required for them to disappear from circulation and for the patient to improve was proportional to the extent of thymic hyperplasia. Seybold et al. (1971) studied the thymic histological appearances in 43 juvenile myasthenics. Ninety-five per cent of the specimens showed evidence of hyperplasia, the extent of which could not be correlated with the remission rate. It is difficult to compare their results with those of Mackay et al. (1968) since the patients studied were much younger and nearly all had thymic hyperplasia compared with only half of the patients in the earlier study. Reinglass and Brickel (1973) were also unable to demonstrate any relationship between the thymic histological appearances and clinical progress in 12 thymectomized patients but, on analysis of their results, it is noteworthy that the only patients who improved greatly or underwent a remission had marked germinal centre hyperplasia. Finally, Vetters and Simpson (1974) made a quantitative histological study and demonstrated a tendency for patients with relatively 'unreactive' thymus glands to improve most after thymectomy but again this could not be confirmed statistically.

The present study includes 23 patients who have had a thymectomy during the past 10 years. Adequate histological material was available and sections were examined without any knowledge of the clinical findings. Eighty-two per cent of patients without a thymoma who had undergone a complete remission or improvement (groups A and B) had numerous germinal centres whereas only $25 \%$ of those who remained the same, deteriorated, or died (group C) had this histological appearance. Sixty-three per cent in group $C$ had no germinal centres demonstrable compared with $9 \%$ in groups $\mathrm{A}$ and $\mathrm{B}$, and atrophy of the thymus gland was seen more commonly in those patients who failed to improve. The majority of patients whose glands were only slightly atrophic or contained numerous germinal centres were young females. These results would seem to agree with those of Mackay et al. (1968) and are indicative of a better prognosis after thymectomy for patients with thymic hyperplasia.

Since the mean postoperative follow-up period was longest in group A (Table 1) and the time required to reach this state varied from six months to $2 \frac{1}{2}$ years, it is possible that with further observation the correlation between the histological findings and the clinical grouping may have changed, although this is unlikely since the number of patients in group B was small and $75 \%$ of patients in group $\mathrm{C}$ had died. To avoid this discrepancy, a clinical and histological assessment of patients was made nine months after thymectomy (Fig. 2) but even during thiso initial period 10 patients with germinal centre hyperplasia had improved and only one had deteriorated.

The possible contribution of pre- and post operative medication has been considered. Two patients in groups $\mathrm{A}$ and $\mathrm{B}$ who had numerous germinal centres received steroids postoperas tively and on both occasions further clinical o improvement occurred. In one patient, steroids were stopped and in another they were reduced to a maintenance dose without any clinical deterioration. While the use of steroids appeared to contribute to the overall postoperative improvement of these two patients, it cannot be accepted that their use was a major factor determining a better prognosis in groups A and B as a whole since they were used far more frequently but with less benefit in group $C$. The administration of steroids preoperatively and the incidence of changes in postoperative anticholinesterase medication did not differ significantly between groups $\mathrm{A}$ and $\mathrm{B}$ and group $\mathrm{C}$.

Two theories have been proposed to relate the histological appearances of the thymus gland with the pathophysiology of myasthenia gravis. Goldstein (1966) has suggested that thymic hyperplasia leads to the production of a neuromuscular blocking agent, while Alpert et al. (1971) have advanced the concept of thymic lymphocytes inducing neuromuscular damage. 
Both theories would be consistent with an improvement in myasthenic symptoms after thymectomy and it is conceivable that the degree of improvement would be proportional to the extent of germinal centre hyperplasia. However the information available is contradictory and the present communication simply increases the evidence in favour of such a correlation. The issue is of more than just theoretical interest because of its possible importance in the selection of patients for thymectomy and as a prognostic indicator.

We are indebted to Dr L. A. Liversedge and Dr R. G. Lascelles for allowing us to study their patients and to $\mathrm{Mr}$ H. F. M. Bassett who performed the thymectomies.

\section{REFERENCES}

Alpert, I. L., Papatestas, A., Kark, A., Osserman, R. S., and Osserman, K. (1971). A histological reappraisal of the thymus in myasthenia gravis. Archives of Pathology, 91, $55-61$.

Blalock, A., Mason, M. F., Morgan, H. J., and Riven, S. S. (1939). Myasthenia gravis and tumors of the thymic region. Annals of Surgery, 110, 544-561.

Castleman, B., and Norris, E. H. (1949). The pathology of the thymus in myasthenia gravis. Medicine (Balt.), 28, 27-58.
Goldstein, G. (1966). Thymitis and myasthenia gravis. Lancet, 2, 1164-1167.

Keynes, G. (1949). The results of thymectomy in myasthenia gravis. British Medical Journal, 2, 611-616.

McEachern, D., and Parnell, J. L. (1948). The relationship of hyperthyroidism to myasthenia gravis. Journal of Clinical Endocrinology, 8, 842-850.

Mackay, I. R., and de Gail, P. (1963). Thymic germinal centres and plasma cells in systemic lupus erythematosus. Lancet, 2, 667.

Mackay, I. R., Whittingham, S., Goldstein, G., Currie, T. T., and Hare, W. S. C. (1968). Myasthenia gravis: Clinical, serological and histological studies in relation to thymectomy. Australian Annals of Medicine, 17, 1-11.

Reinglass, J. L., and Brickel, A. C. J. (1973). The prognostic significance of thymic germinal centre proliferation in myasthenia gravis. Neurology (Minneap.), 23, 69-72.

Schumacher, M., and Roth, J. (1913). Thymektomie bei einem Fall von Morbus Basedowi mit Myasthenie. Mitteilungen aus den Grenzgebieten der Medizin und Chirurgie, 25, 746-758.

Seybold, M. E., Howard, F. M., Duane, D. D., Payne, W. S., and Harrison, E. G. (1971). Thymectomy in juvenile myasthenia gravis. Archives of Neurology, 25, 385-392.

Sloan, H. E. (1943). The thymus in myasthenia gravis. Surgery, 13, 154-174.

Vetters, J. M., and Simpson, J. A. (1974). Comparison of thymic histology with response to thymectomy in myasthenia gravis. Journal of Neurology, Neurosurgery, and Psychiatry, 37, 1139-1145.

Weigert, C. (1901). Pathologisch-anatomischer Beitrag zur Erbschen Krankheit. Archiv für Psychiatrie und Nervenkrankheiten, 34, 1063-1081. 